\title{
An avian influenza $A($ H11N1) virus from a wild aquatic bird revealing a unique Eurasian-American genetic reassortment
}

\author{
Shailesh Pawar • Alok Chakrabarti - Sarah Cherian - Satish Pande • \\ Madhuri Nanaware · Satish Raut • Biswajoy Pal • Santosh Jadhav • \\ Sadhana Kode $\cdot$ Santosh Koratkar $\cdot$ Vishal Thite $\cdot$ Akhilesh Mishra
}

Received: 7 January 2010/Accepted: 19 April 2010/Published online: 4 May 2010

(C) The Author(s) 2010. This article is published with open access at Springerlink.com

\begin{abstract}
Influenza surveillance in different wild bird populations is critical for understanding the persistence, transmission and evolution of these viruses. Avian influenza (AI) surveillance was undertaken in wild migratory and resident birds during the period 2007-2008, in view of the outbreaks of highly pathogenic AI (HPAI) H5N1 in poultry in India since 2006. In this study, we present the whole genome sequence data along with the genetic and virological characterization of an Influenza $\mathrm{A}(\mathrm{H} 11 \mathrm{~N} 1)$ virus isolated from wild aquatic bird for the first time from India. The virus was low pathogenicity and phylogenetic analysis revealed that it was distinct from reported H11N1 viruses. The hemagglutinin (HA) gene showed maximum similarity with A/semipalmatedsandpiper/Delaware/2109/2000 (H11N6) and A/shorebird/Delaware/236/2003(H11N9) while the neuraminidase (NA) gene showed maximum similarity with A/duck/Mongolia/540/2001(H1N1). The virus thus possessed an HA gene of the American lineage. The NA and other six genes were of the Eurasian lineage and showed
\end{abstract}

Electronic supplementary material The online version of this article (doi:10.1007/s11262-010-0487-2) contains supplementary material, which is available to authorized users.

S. Pawar - A. Chakrabarti $\cdot$ S. Cherian $\cdot$ M. Nanaware .

S. Raut - B. Pal - S. Jadhav - S. Kode - S. Koratkar - V. Thite

A. Mishra

National Institute of Virology, Microbial Containment Complex,

130/1, Sus Road, Pashan, Pune 411021, India

S. Pande

Ela Foundation, C-9, Bhosale Park, Sahakarnagar No. 2,

Pune 411009, India

A. Mishra ( $\square)$

National Institute of Virology, 20-A, Dr Ambedkar Road,

Pune 411001, India

e-mail: acm1750@rediffmail.com closer relatedness to non-H11 viruses. Such a genetic reassortment is unique and interesting, though the pathways leading to its emergence and its future persistence in the avian reservoir is yet to be fully established.

Keywords Avian influenza - Surveillance · Eurasian Spoonbill · Unique H11N1 virus · Reassortment · India

\section{Introduction}

Type A influenza viruses belong to the family Orthomyxoviridae. They are divided into subtypes based on the serogrouping of 16 hemagglutinin (HA) and 9 neuraminidase (NA) genes. Wild aquatic birds, such as geese, shorebirds and wild ducks are the natural reservoirs of influenza A viruses [1]. At least 103 of the possible 144 type A Influenza virus HA-NA combinations have been found in wild birds [2].

Avian influenza (AI) surveillance in different waterfowl and wild bird populations is critical to our understanding of the persistence, transmission and evolution of these viruses. The migratory nature of many waterfowl species and the persistence of influenza in these populations present a vehicle for dissemination of AI viruses globally [3]. A recent study [4] documented genetic diversity among AI viruses in wild birds, based on 167 complete genomes from 14 bird species sampled in the US and reported a high rate of genome reassortment and occasional inter-hemisphere gene segment migration.

In India, there have been occasional reports on the isolation of AI viruses namely H4N2, H9N2, H9N3, H2N2 and H3N2 from avian species in the states of northern and southern India [5, 6]. Furthermore, India reported outbreaks 
of highly pathogenic avian influenza (HPAI) H5N1 in poultry in the western states of Maharashtra, Gujarat, Madhya Pradesh and North Eastern states of Manipur, West Bengal, Tripura and Assam during the period spanning from 2006 to 2009 [7-10]. Though migratory birds may have a role to play in the introduction of different AI viruses in the country, there is very limited data with regard to the AI viruses harboured in them. Therefore, in view of these recent AI H5N1 outbreaks in poultry in India, screening of wild migratory and wild resident birds was undertaken by the National Institute of Virology (NIV) jointly with the Ela Foundation, Pune, India to study the role of these birds in the transmission of AI viruses.

Migratory birds are found in India during the period from October to April. The surveillance activity was carried out during the winter migratory season 2007-2008. During this season, several fresh water and coastal wetlands in the states of Maharashtra, Karnataka and Goa states were visited for sampling. We report here the findings of the isolation of $\mathrm{AI} A(\mathrm{H} 11 \mathrm{~N} 1)$ virus during this surveillance from one site, Rui-Chhatrapati village, Maharashtra, India. The study describes the isolation and characterization of $\mathrm{AI} A(\mathrm{H} 11 \mathrm{~N} 1)$ virus from a wild aquatic bird, Eurasian Spoonbill (Platalea leucorodia), for the first time from India.

\section{Materials and methods}

\section{Collection of fecal samples (FS)}

Assemblages of several apparently healthy avian species were recorded resting on the banks of the percolation tank at Rui-Chhatrapati village, Taluk Parner, Ahmednagar district, Maharashtra, India. This village is geographically located between the towns of Ahmednagar $\left(19.08^{\circ} \mathrm{N}, 74.73^{\circ} \mathrm{E}\right)$ and Visapur $\left(18.96^{\circ} \mathrm{N}, 74.70^{\circ} \mathrm{E}\right)$. The avian species were identified following standard field guides. In order to ensure that the fecal samples (FS) were from the identified species, only fresh and wet FS were collected following the Food and Agriculture Organization (FAO) guidelines [11]. Samples were collected from pure or separately standing flocks of the same species while they were resting after the foraging activity. In addition to prior identification of the species, the FS were morphologically characterized based on physical (colour and size) and biochemical $(\mathrm{pH})$ attributes. All the FS were collected in Viral Transport Medium [VTM (Hank's balanced salt solution with Penicillin, Streptomycin, Gentamycin, Amphotericin B)], immediately sealed and transferred in cold chain to the laboratory.

The total avian population irrespective of the species recorded in the assemblage was approximately 800 birds. A total of $250 \mathrm{FS}$ of 12 avian species (Ten avian families:
Ardeidae, Ciconiidae, Threskiornithidae, Anatidae, Charadriidae, Glareolidae, Sternidae, Muscicapidae, Timaliidae, Sturnidae) were collected. Of these, on the basis of physical and biochemical analysis (data not shown) 60 FS were identified as belonging to Eurasian Spoonbills.

\section{Virus isolation}

A total of 50 pooled FS were obtained from the $250 \mathrm{FS}$ by pooling five FS of the same species. All the 50 pooled FS were processed for virus isolation in 10-day-old specific pathogen free (SPF) embryonated chicken eggs. The contents of the collection vial were homogenized; the vials were centrifuged at 2,000 rpm for $5 \mathrm{~min}$ to remove debris. Three aliquots were made of which one was used for inoculation in SPF eggs (Venky's India Limited, Pune, India) [12]. Each sample was inoculated in two eggs by the allantoic route. Eggs were incubated at $37^{\circ} \mathrm{C}$ for $72 \mathrm{~h}$, were chilled at $+4^{\circ} \mathrm{C}$ overnight, and allantoic fluids were harvested.

For virus isolation in Madin-Darby Canine Kidney (MDCK) cell line, a confluent cell monolayer in T-25 flasks was infected with $500 \mu \mathrm{l}$ of the virus inoculum, allowed to adsorb for $30 \mathrm{~min}$ at $37^{\circ} \mathrm{C}$. Flasks containing virus inoculum and $5 \mathrm{ml}$ of DMEM containing $2 \mu \mathrm{g} / \mathrm{ml}$ of Tosyl Phenylalanyl Chloromethyl Ketone (TPCK)-treated trypsin without calf serum were then incubated at $37^{\circ} \mathrm{C}$ for 4-6 days. The flasks were observed daily for cytopathic effect (CPE). Cell cultures were harvested when $\sim 75 \%$ of the total cells in the monolayer showed CPE. The tissue culture supernatants were tested by hemagglutination (HA) assay using $0.5 \%$ fowl and $1 \%$ horse red blood cells (RBCs) [12]. RBCs from different species were tested in separate HA assays.

\section{Virus detection and identification}

The allantoic fluids from inoculated SPF eggs were screened by HA assay for detection of viruses. RBCs from both horse and fowl were separately used for the HA and the hemagglutination inhibition (HI) assays [12]. HI assay was performed for virus identification using Influenza A H1 to H16 antisera (OIE/FAO National Reference Laboratory for AI and Newcastle disease, Legnaro, Italy). Influenza A(H11) antisera were kindly provided by Dr. William Dundon, OIE/ FAO National Reference Laboratory for AI and Newcastle disease, Legnaro, Italy.

\section{Virological characterization}

Virus titration was performed by inoculating the virus diluted from $10^{-1}$ to $10^{-10}$. Each dilution was inoculated by the allantoic route in four 10-day-old SPF embryonated 
chicken eggs. Allantoic fluids from the inoculated eggs were harvested and tested by the HA assay. Allantoic fluids showing titer in the HA assay ( $\geq 2$ HA units) were considered positive for virus replication. Fifty percent egg infectious dose $\left(\operatorname{EID}_{50}\right)$ titers were calculated using the Reed and Muench method [13]. Virus titration in MDCK cell line using a microneutralization (MN) assay was performed as per Rowe et al. [14].

RBCs of avian and mammalian species $(0.5 \%$ fowl, $1 \%$ horse, $0.75 \%$ guinea pig, $0.5 \%$ goose and $0.5 \%$ turkey $\mathrm{RBCs}$ ) were used in separate HA assays to determine the sialic acid receptor specificity of the virus isolate [15]. MDCK cells infected with the AI isolate were tested by an indirect immunofluorescence (IF) assay to type the influenza A virus using influenza A-specific monoclonal antibodies conjugated with fluorescein isothiocyanate (Chemicon, USA).

Molecular detection using reverse transcriptase polymerase chain reaction (RT-PCR)

All the pooled FS and HA positive allantoic fluids were tested in RT-PCR for the presence of influenza A viruses by standard one-step RT-PCR, using influenza type-Aspecific primers [10]. Viral RNA was extracted using QIAamp viral RNA mini kit (Qiagen Inc, Germany). Influenza A HA-specific primers (HA-1144F and HA R) and NA (N1) specific primers (N1-1 and N1-2) were used to detect the HA and NA genes, respectively [16].

Whole genome sequencing

RNA isolated from the original FS and allantoic fluid was reverse transcribed [8]. cDNA prepared was used for PCR amplification (ROCHE Hi-Fi PCR system, Roche, Germany) of all of the eight gene segments using influenza virus segment specific primers [10]. The PCR products were analyzed by agarose gel electrophoresis and purified from gel using a gel extraction kit (QIAGEN, Germany). Amplicons were directly sequenced using the BigDye ${ }^{\circledR}$ Terminator v 3.1 Cycle Sequencing Kit in an automated 3130 XL Genetic analyzer (Applied Biosystems). Primers specific for H11 (HA) were designed and used for amplification and sequencing. The primer sequences were:

417F: 5'-ACCTCAAGTGGATGGGGAG-3', 679F:5'-TAC AACAGGAGGTTCACTCCT-3'

886F: 5'-TGCTCAACTAAATGCCAGTCC-3', 1049F:

5'-TGTTTGGTGCAATAGCTGG-3'

1317F: 5'-ATGGTCATACAACGCACAGC-3' 417R: 5'-CT CCCCATCCACTTGAGG-3'

679R: 5'-CAGGAGTGAACCTCCTGTTG-3', 886R: 5'-CG GACTGGCATTTAGTTGAGC- $3^{\prime}$
1049R: 5'-CCAGCTATTGCACCAAAC-3', 1317R: 5'GCTGTGCGTTGTATGACCAT-3'

For sequencing of the other genes, segment-specific primers as described earlier [8] were used. The accession numbers of the sequences deposited in the GenBank are from CY055172 to CY055179.

Phylogenetic analysis

A phylogenetic tree for the HA gene was constructed using all the available sequences of H11 subtypes. For the NA gene, representative viruses from different lineages of the N1 subtype were used. In addition, for the NA gene and internal gene segments, the top BLAST hits to each segment of the H11N1 Indian virus isolate were used. The neighbour joining method with the Kimura 2 parameter distance model in MEGA 3.1 [17] was used, with 1000 bootstrap replicates. The percent nucleotide identity (PNI) and percent amino acid identity (PAI) values were calculated as pair-wise p-distances. The tree topologies were verified by using the Parsimony method, also available in MEGA 3.1. The HA gene tree was rooted at A/duck/ England/1/1956(H11N6), the NA gene tree was rooted at A/Brevig Mission/1/1918 (H1N1) while the trees for the internal genes were rooted at the A/Puerto Rico/8/ 1934(H1N1) isolate. As representations of the HA, NA and matrix gene phylogenetic trees (Fig. 1) and the phylogeny of the other five genes (Supplementary Figs. S1-S5) all the available gene sequences of the H11N1 isolates from the GenBank were included. However, for the purpose of clarity, representative sequences of the other H11 subtypes were selected by excluding the $100 \%$ identical sequences and further considering a geographical representation. For BLAST hits of NA and other genes, the representatives of the top $1-2 \%$ hits were selected.

\section{Results}

Virus isolation and identification

In the present study, 50 pooled FS were processed for virus isolation in embryonated chicken eggs. Only one pooled FS was positive for influenza A virus by virus isolation and RT-PCR. This sample was collected from a flock of wild migratory aquatic birds identified as Eurasian Spoonbill. The above sample showed a titer of 512 HA units (HAU) with both $0.5 \%$ fowl and $1 \%$ horse RBCs in the HA assay. The egg-isolate reacted with $\mathrm{AI}$ A(H11) antisera in the HI assay with a titer of 320 . All other subtype sera did not react with this virus isolate (titer $<10$ ). Thus, this virus 


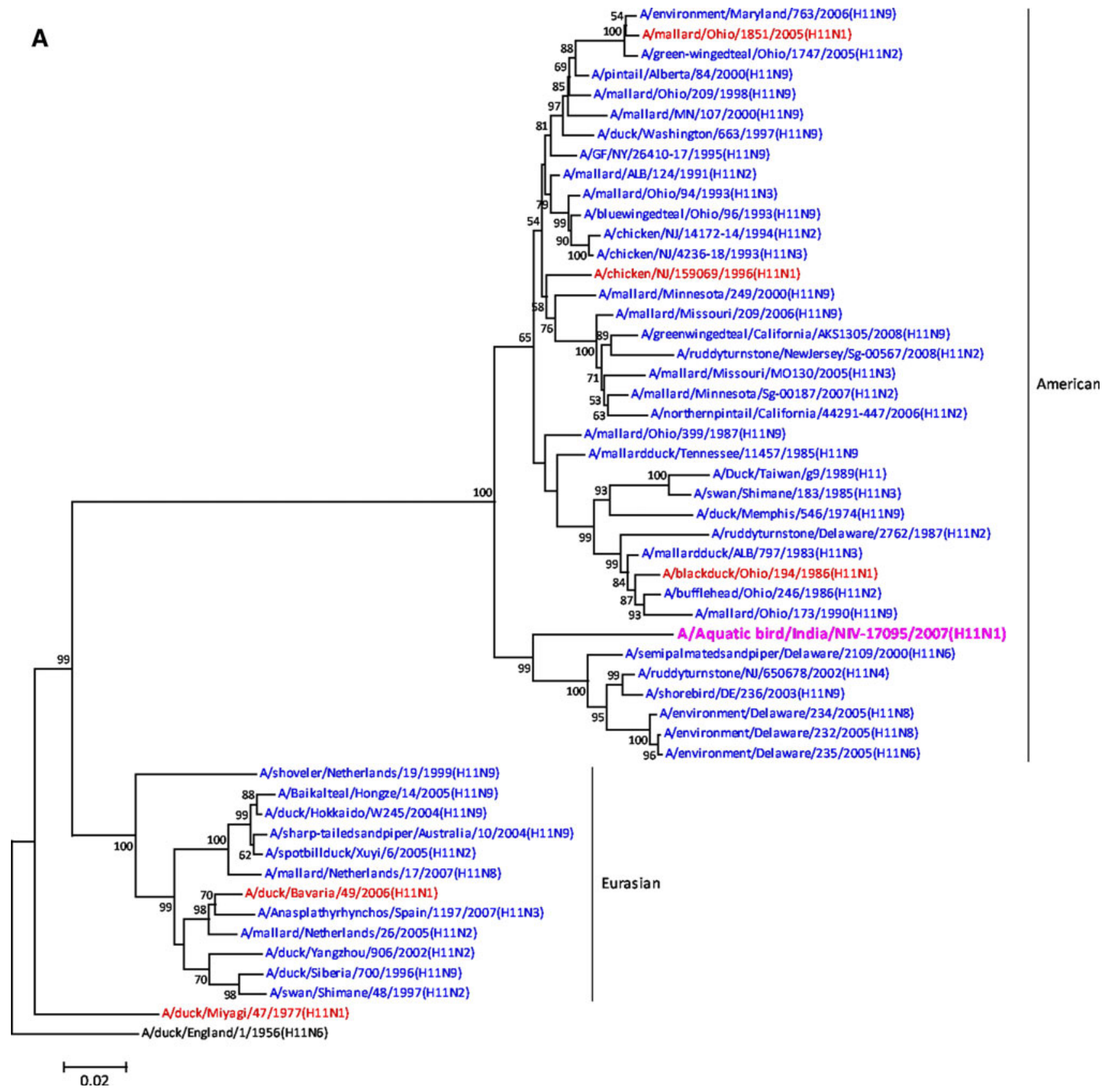

Fig. 1 Phylogenetic trees constructed by the neighbour joining method as implemented in MEGA. Scale bar indicates the number of nucleotide substitutions per site. Highlighted in magenta is the Indian $\mathrm{H} 11 \mathrm{~N} 1$ isolate, the other $\mathrm{H} 11 \mathrm{~N} 1$ isolates are shown in red,

isolate was serologically identified as influenza A (H11). Complete sequencing of the HA and NA genes confirmed this isolate (A/Aquatic bird/India/NIV-17095/2007) as an influenza $A(H 11 N 1)$ subtype.

Virological characterization

No mortality was observed when 10-day-old chicken embryos were inoculated with the H11N1 virus that was while other H11 subtypes are in blue. The top BLAST hits for the neuraminidase and matrix genes are shown in green. a Hemagglutinin gene, $\mathbf{b}$ neuraminidase gene, $\mathbf{c}$ matrix gene

isolated in this study. $\mathrm{EID}_{50}$ of this virus isolate was $10^{8.25}$. The virus reacted with fowl, guinea pig, goose and turkey RBCs (HA titer: $1024 \mathrm{HAU}$ ) and with horse RBCs (HA titer: 512 HAU) indicating specificity to both avian and mammalian sialic acid receptors. The virus grew in a MDCK cell line (HA Titer: $512 \mathrm{HAU}$ ) and the 50\% Tissue Culture Infectious Dose was $10^{4.33}$ by a MDCK cell assay [14]. An indirect IF assay in infected MDCK cells showed bright apple-green fluorescence in the cytoplasm and in the nucleus 


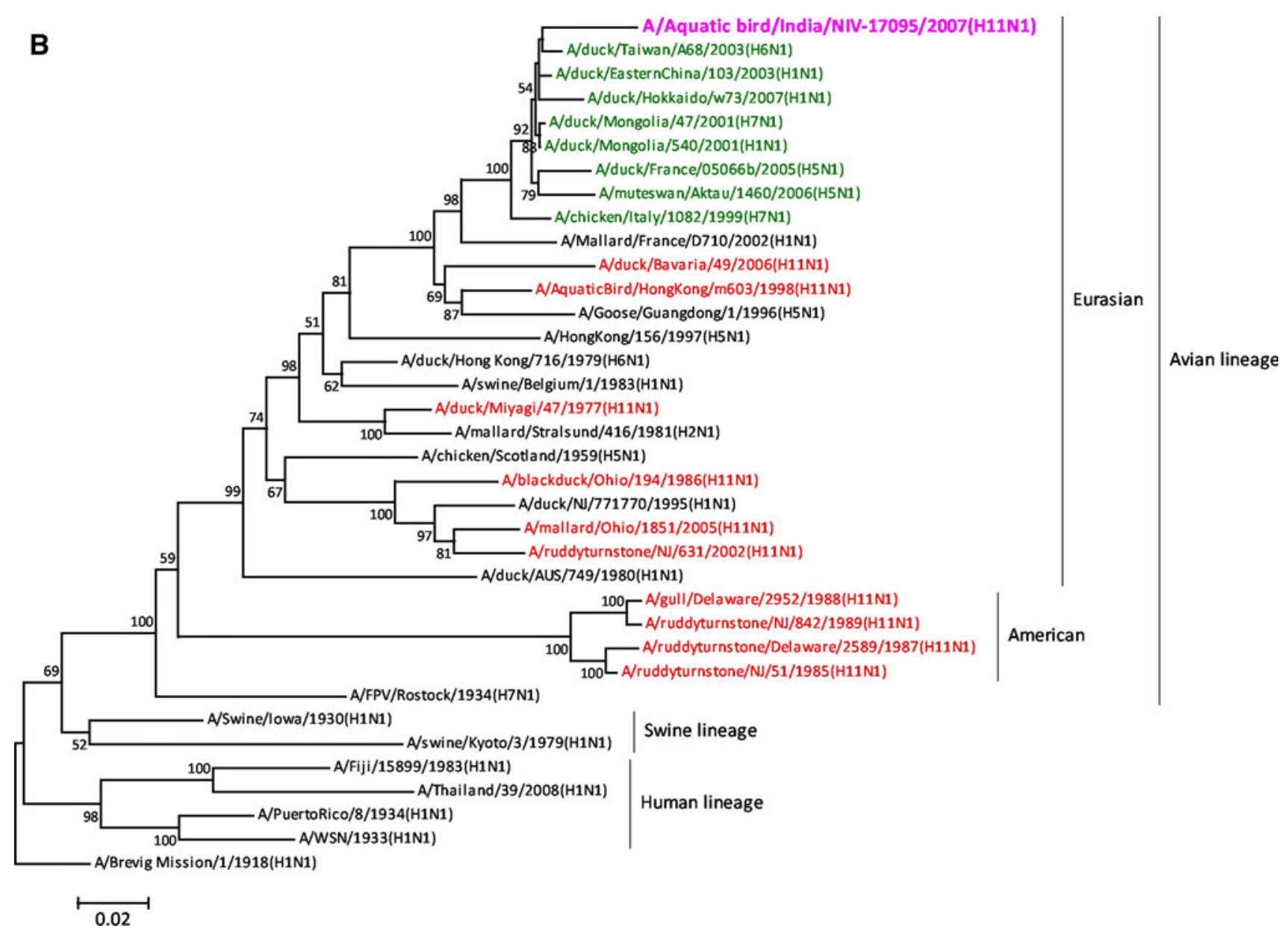

Fig. 1 continued

of the cells, showing $\mathrm{AI} A(\mathrm{H} 11 \mathrm{~N} 1)$ virus replication in MDCK cells (data not shown).

Sequence and phylogenetic analyses

Whole genome sequencing of all the eight segments was performed to characterize the Indian $\mathrm{H} 11 \mathrm{~N} 1$ virus. The sequence analysis of the HA gene showed absence of the multibasic amino acids at the cleavage site [18], indicating that the virus isolate was a low pathogenicity avian influenza (LPAI).

Phylogenetic analysis of the HA and other gene sequences (Fig. 1 and Supplementary Figs. S1-S5) demonstrated the divergence of the $\mathrm{H} 11$ virus subtypes into two distinctly different lineages generally referred to as the American and Eurasian lineages.

\section{Hemagglutinin gene}

In the HA gene tree (Fig. 1a), the A/Aquatic bird/India/ NIV-17095/2007 isolate fell into the American lineage.
The isolate did not cluster with other H11N1 isolates but showed relatedness to a cluster consisting of Delaware (United States) H11N6/N8/N9 isolates of 2000/2003/2005 and an H11N4 isolate of New Jersey (NJ)/2002, from shorebirds and environmental samples. At the nucleotide level, the Indian isolate showed maximum identity with A/semipalmatedsandpiper/Delaware/2109/2000(H11N6) (PNI 93.27 and PAI 93.98). At the amino acid level, the maximum identity was with A/shorebird/DE/236/03 (H11N9) (PNI 92.5, PAI 94.5) (Table 1). The substantial divergence of $\sim 7 \%$ is reflected by the long branch length to the A/Aquatic bird/India/NIV-17095/2007 isolate in the phylogenetic tree. The isolate differed from other H11N1 isolates with PNIs between 89.79 and 92.04 (PAI 92.74-93.04). No HA gene sequence of any Asian H11N1 virus was available in the GenBank for comparison. Only two other Asian H11 isolates, A/swan/ Shimane/183/85 (H11N3) and A/duck/Taiwan/g9/89 (H11), were found in the American lineage with PNI between 88.15 and 89.85 (PAI 90.63-92.92) with the Indian isolate. 


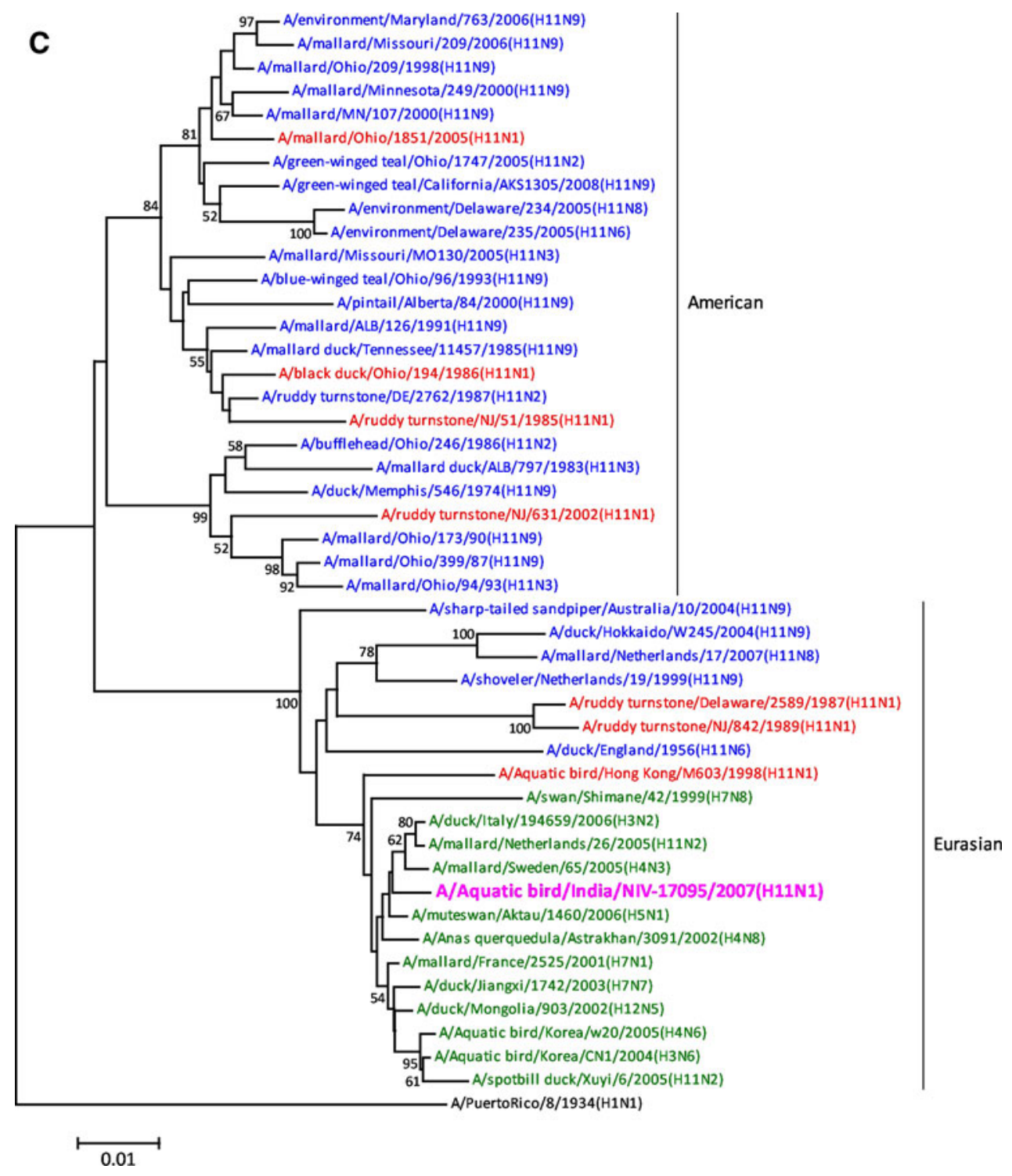

Fig. 1 continued

\section{Neuraminidase gene}

The phylogenetic tree based on the NA gene (Fig. 1b), showed the three lineages corresponding to avian, human and swine influenza A viruses. The Indian isolate, A/Aquatic bird/India/NIV-17095/2007, clustered with other Eurasian avian viruses. Though all the other available $\mathrm{H} 11 \mathrm{~N} 1$ isolates also fell into the avian lineage, the closest neighbours of the Indian $\mathrm{H} 11 \mathrm{~N} 1$ virus included isolates from several non-H11 subtypes including H1N1, H7N1, H5N1, H6N1 from duck species from Mongolia, Taiwan, Eastern China and some European countries. The divergence between the Indian isolate and the closest relative, A/duck/Mongolia/540/2001 (H1N1) was 2.91 and $1.07 \%$ (Table 1) at the nucleotide and amino acid level, respectively. The Indian isolate differed from the other Asian H11N1 isolate (Aquatic bird/ HongKong/M603/1998) by $7.62 \%$ at the nucleotide level and $2.86 \%$ at the amino acid level. Other $\mathrm{H} 11 \mathrm{~N} 1$ isolates in the Eurasian lineage differed from the Indian isolate by approximately 9-14\% (3-6\%) at the nucleotide (amino acid) level.

\section{Matrix and other genes}

The phylogenetic tree for the matrix gene showed that the H11N1 Indian isolate clustered in the Eurasian lineage with closest relatives including subtypes H5N1, H4N8, H4N3, H11N2, H3N2, H7N1, H7N8, H12N5, predominantly from duck species from Aktau, Astrakhan, Mongolia, Korea and Europe and the A/Aquatic bird/Hong Kong/M603/1998 
Table 1 Percent nucleotide identity (PNI) and percent amino acid identity (PAI) between A/Aquatic bird/India/NIV-17095/2007(H11N1) and the closely related isolates

\begin{tabular}{llllr}
\hline Gene & $\begin{array}{l}\text { GenBank accession number } \\
\text { of A/Aquatic bird/India/NIV- } \\
\text { 17095/2007 (H11N1) isolate }\end{array}$ & $\begin{array}{l}\text { Length nucleotide } \\
\text { (amino acid) }\end{array}$ & Name of closely related isolates & PNI \\
\hline PB2 & CY055172 & $2277(759)$ & A/duck/Jiang Xi/3345/2005(H5N2) & 97.15 \\
PB1 & CY055173 & $2271(757)$ & A/mute swan/Hungary/5973/2007(H7N7) & 99.47 \\
PA & CY055174 & $2148(716)$ & A/teal/Italy/3812/2005(H5N3) & 99.87 \\
HA & CY055175 & $1695(565)$ & A/semipalmatedsandpiper/Delaware/2109/2000(H11N6) & 93.27 \\
& & & A/shorebird/DE/236/03(H11N9) & 93.98 \\
NP & CY055176 & $1494(498)$ & A/mute swan/Aktau/1460/2006(H5N1) & 92.5 \\
NA & CY055177 & $1407(469)$ & A/duck/Mongolia/540/2001(H1N1) & 94.5 \\
M & CY055178 & 979 & A/mute swan/Aktau/1460/2006(H5N1) & 100 \\
M1 & CY055178 & $756(252)$ & A/mute swan/Aktau/1460/2006(H5N1) & 97.18 \\
NS & CY055179 & 841 & A/mallard/Yan chen/2005(H4N6) & 98.93 \\
NS1 & CY055179 & $690(230)$ & A/mallard/Yan chen/2005(H4N6) & - \\
\hline
\end{tabular}

(H11N1) isolate (Fig. 1c). The PNI between the Indian isolate and its closest relative isolate $\mathrm{A} /$ mute swan/Aktau/1460/ 2006(H5N1) was 99.28 while with A/Aquatic bird/Hong Kong/M603/1998(H11N1) it was 97.55.

The other internal genes of the Indian H11N1 isolate indicated similar clustering in the Eurasian lineage (Supplementary Figs. S1-S5). The nucleotide and amino acid identities with the closest relative isolates on the basis of BLAST hits are indicated in Table 1.

\section{Discussion}

Though India reported outbreaks of HPAI H5N1 in different parts of the country, including Maharashtra, during 2006-2009, in the present study, none of the samples were positive for HPAI H5N1 [19]. During this study period AI $\mathrm{A}(\mathrm{H} 11 \mathrm{~N} 1)$ was isolated from FS of a flock of aquatic birds identified as Eurasian Spoonbills. As only one of the 50 pooled FS studied was positive, it shows that this virus was not habitually present in the birds. Isolation of $\mathrm{AI}$ $\mathrm{A}(\mathrm{H} 11 \mathrm{~N} 1)$ and $\mathrm{A}(\mathrm{H} 11 \mathrm{~N} 9)$ has been recently reported in Northern pintails (Anas acuta) in Japan [20]. There are reports of influenza $\mathrm{A}(\mathrm{H} 11 \mathrm{~N} 1)$ from Hong Kong, the United States of America and Japan from Black duck, chicken, duck, gull, mallard and ruddy turnstone. This is the first report of an isolation and characterization of an AI H11N1 virus from aquatic birds from India. To the best of our knowledge, to date, there has been no report of isolation of influenza A H11 virus from Spoonbills.

The virological characterization and sequence analysis of the H11N1 virus in this study showed that it was LPAI. To further characterize the virus, phylogenetic analyses were carried out. Similar to many other influenza A virus HA subtypes, the H11 viruses, on the whole separated into geographically distinct lineages namely American and Eurasian. These two lineages largely correspond to avian isolates from the Western and Eastern hemisphere, respectively [21, 22]. Phylogenetic analysis revealed that the virus was distinct from the other available H11N1 viruses. Based on available genetic data of NA, M, NP and NS genes, the only other Asian H11N1 isolate, Aquatic bird/HongKong/M603/1998 can be said to be of a Eurasian origin. However, due to the non-availability of the sequences of the other gene segments including the HA gene of this isolate in GenBank, the origin of the H11 HA gene for the Hong Kong isolate cannot be ascertained. The Indian isolate was characterized as a reassortant possessing a Eurasian origin on the basis of the NA and other six internal genes and an American origin in the HA gene. The possibility of reassortment during processing pooled FS for virus isolation was verified by sequencing the virus from the original pooled FS and the virus isolated from embryonated chicken eggs. The sequences of the virus from the original pooled FS and virus isolate were similar (data not shown), thus ruling out this possibility.

In the HA gene the Indian isolate was more closely related to non-H11N1 viruses, namely, A/semipalmatedsandpiper/ Delaware/2109/2000(H11N6) and A/shorebird/Delaware/ 236/2003(H11N9). The NA gene showed maximum identity with A/duck/Mongolia/540/2001(H1N1). Likewise in all the internal genes the Indian H11N1 isolate showed maximum relatedness with non-H11 viruses. Thus, the virus isolate under study showed a unique genetic reassortment between Eurasian and American lineages. There have been reports where occasionally the AI isolates have demonstrated hemispheric mixing with reassortment [4] which can be attributed to overlapping migratory bird flyways [23]. Most mixed isolates possess only one gene segment derived from the other hemisphere, indicating that there is less survival 
advantage for such crossovers in the new gene pool [4]. Our phylogenetic analysis also revealed that other H11N1 strains are reassortents. Isolates such as A/blackduck/Ohio/194/ 1986 and A/mallard/Ohio/1851/2005 belonged to the American lineage but possessed an NA gene of the Eurasian lineage while isolates such as $\mathrm{A} / \mathrm{ruddy}$ turnstone/Delaware/ 2589/87 and A/ruddyturnstone/NJ/842/1989 had a majority of their genes of Eurasian origin. In all these cases however, the viruses were closely related to other H11N1 viruses. There are also reports that the majority of such hemispheric mixing has been observed in shorebirds and gulls [24]. Notably, the Indian isolate possessed an HA gene which was closely related to the HA of isolates from environmental samples and shorebirds migrating through the Delaware bay area (USA), while the other genes of our isolate were found to be close to isolates mainly from duck species of Eurasian regions. This therefore reveals a possible role of such shorebirds and wild aquatic birds in contributing to the gene pool mixing of the H11 viruses. A recent study wherein the role of free flying birds in the genetic reassortment has been reported, showed that $\mathrm{H} 2$ viruses in Australia were found to be Eurasian-American reassortents [25].

Furthermore, the evolutionary distance especially in the HA gene between the H11N1 isolate under study and its closest relatives may indicate a lack of AI surveillance in waterfowl and wild bird populations. Though our H11N1 isolate is the first isolation from the Spoonbill species it is not unlikely that similar viruses have been existed in the same or related species even earlier. In a recent report, H5N1 virus was isolated from the Eurasian spoonbill [26].

Overall, the characterization of the LPAI H11N1 from a wild aquatic bird, Eurasian spoonbill, revealed that the virus is a unique combination of influenza virus gene segments, involving the reassortment of a North American H11 HA in a background of Eurasian genes. This kind of genetic reassortment is interesting as it demonstrates the diversity of influenza virus variants that can be harboured in migrating wild birds. However, the pathways leading to its emergence and its future persistence in the avian reservoir is yet to be fully understood. Importantly active AI surveillance in both migratory and resident avian species is further required to track the existing, as well as the evolving, strains of the AI viruses.

Acknowledgements We thank Mr. MR Khude, Mr. SK Waghmare, Miss. DS Hangekar, Mr. VR Ghule and Mr. NS Jagtap for laboratory assistance and Dr. J. Mullick for support. Thanks are due to Ela foundation members Amit Pawashe, Aditya Ponkshe, Pranav Pandit and Pramod Deshpande for assistance in the fieldwork. We are thankful to Dr. VS Padbidri, Research Director, KEM hospital, Pune, for support. The authors acknowledge the financial support provided by the Indian Council of Medical Research, New Delhi, India.
Open Access This article is distributed under the terms of the Creative Commons Attribution Noncommercial License which permits any noncommercial use, distribution, and reproduction in any medium, provided the original author(s) and source are credited.

\section{References}

1. K.M. Sturm-Ramirez, D.J. Hulse-Post, E.A. Govorkova, J. Humberd, P. Seiler, P. Puthavathana et al., Are ducks contributing to the endemicity of highly pathogenic H5N1 influenza virus in Asia? J. Virol. 79, 11269-11279 (2005)

2. D.J. Alexander, An overview of the epidemiology of avian influenza. Vaccine 25, 5637-5644 (2006)

3. P.J. Feroo, J. El-Attrache, X. Fang, S.N. Rollo, A. Jester, T. Merendino et al., Avian influenza surveillance in hunter-harvested waterfowl from the gulf coast of Texas (November 2005January 2006). J. Wildlife Dis. 44, 434-439 (2008)

4. V.G. Dugan, R. Chen, D.J. Spiro, N. Sengamalay, J. Zaborsky, E. Ghedin, et al., The evolutionary genetics and emergence of avian influenza viruses in wild birds. PLoS Pathog. 4, e1000076 (2008)

5. B.L. Rao, Epidemiology and control of influenza. Natl Med. J. India 16(3), 143-149 (2003)

6. S. Nagarajan, K. Rajukumar, C. Tosh, V. Ramaswamy, K. Purohit, G. Saxena et al., Isolation and pathotyping of H9N2 avian influenza viruses in Indian poultry. Vet. Microbiol. 133, 154-163 (2009)

7. M. Khanna, P. Kumar, K. Choudhary, B. Kumar, V.K. Vijayan, Emerging influenza virus: a global threat. J. Biosci. 34, 475-482 (2008)

8. A.C. Mishra, S.S. Cherian, A.K. Chakrabarti, S.D. Pawar, S.M. Jadhav, B. Pal et al., A unique influenza A (H5N1) virus causing a focal poultry outbreak in 2007 in Manipur, India. Virol. J. 6, 26 (2009)

9. B. Pattnaik, A.K. Pateriya, R. Khandia, C. Tosh, S. Nagarajan, S. Gounalan et al., Phylogenetic analysis revealed genetic similarity of the H5N1 avian influenza viruses isolated from HPAI outbreaks in chickens in Maharashtra, India with those isolated from swan in Italy and Iran. Curr. Sci. 91, 77-81 (2006)

10. K. Ray, V.A. Potdar, S.S. Cherian, S.D. Pawar, S.M. Jadhav, S.R. Waregaonkar et al., Characterization of the complete genome of influenza A (H5N1) virus isolated during the 2006 outbreak in poultry in India. Virus Genes 36, 345-353 (2008)

11. FAO, Animal production and health Manual, Wild birds and avian influenza; An introduction to applied field research and disease sampling techniques (2007)

12. WHO, Manual on Animal influenza diagnosis and surveillance, WHO/CDS/CSR/NCS/2002.5

13. L.J. Reed, H. Muench, A simple method for estimating fifty percent endpoints. Am. J. Hyg. 27, 493-497 (1938)

14. T. Rowe, R.A. Abernathy, J. Hu-Primmer, W.W. Thompson, $\mathrm{X}$. Lu, W. Lim et al., Detection of antibody to avian influenza A (H5N1) virus in human serum by using a combination of serologic assays. J. Clin. Microbiol. 37, 937-943 (1999)

15. S. Louisirirotchanakul, H. Lerdsamran, W. Wiriyarat, K. Sangsiriwut, K. Chaichoune, P. Pooruk et al., Erythrocyte binding preference of avian influenza H5N1 viruses. J. Clin. Microbiol. 45, 2284-2286 (2007)

16. K.Y. Yuen, P.K. Chan, M. Peiris, D.N. Tsang, T.L. Que, K.F. Shortridge et al., Clinical features and rapid viral diagnosis of 
human disease associated with avian influenza A H5N1 virus. Lancet 14(351), 467-471 (1998)

17. S. Kumar, K. Tamura, M. Nei, MEGA3: integrated software for molecular evolutionary genetics analysis and sequence alignment. Brief. Bioinform. 5, 150-163 (2004)

18. A.K. Chakrabarti, S.D. Pawar, S.S. Cherian, S.S. Koratkar, S.M. Jadhav, B. Pal et al., Characterization of the influenza A H5N1 viruses of the 2008-09 outbreaks in India reveals a third introduction and possible endemicity. PLoS One 16, 7846 (2009)

19. S.D. Pawar, S. Pande, A. Jamgaonkar, S.S. Koratkar, B. Pal, S. Raut, M. Nanaware et al., Avian influenza surveillance in wild migratory, resident, domestic birds and in poultry in Maharashtra and Manipur, India, during avian migratory season 2006-2007. Curr. Sci. 97, 550-554 (2009)

20. A. Jahangir, Y. Watanabe, O. Chinen, S. Yamazaki, K. Sakai, M. Okamura et al., Surveillance of avian influenza viruses in Northern pintails (Anas acuta) in Tohoku District, Japan. Avian Dis. 52, 49-53 (2008)

21. S. Liu, K. Ji, J. Chen, D. Tai, W. Jiang, G. Hou et al., Panorama phylogenetic diversity and distribution of type a influenza virus. PLoS One 4, e5022 (2009)
22. S. Krauss, C.A. Obert, J. Franks, D. Walker, K. Jones, P. Seiler et al., Influenza in migratory birds and evidence of limited intercontinental virus exchange. PLoS Pathog. 3(11), e167 (2007)

23. A.M. Kilpatrick, A.A. Chmura, D.W. Gibbons, R.C. Fleischer, P.P. Marra, P. Daszak, Predicting the global spread of H5N1 avian influenza. Proc Natl Acad Sci USA 103, 19368-19373 (2006)

24. L. Widjaja, S.L. Krauss, R.J. Webby, T. Xie, R.G. Webster, Matrix gene of influenza A viruses isolated from wild aquatic birds: ecology and emergence of influenza A viruses. J. Virol. 78, 8771-8779 (2004)

25. N. Kishida, Y. Sakoda, M. Shiromoto, G.R. Bai, N. Isoda, A. Takada et al., H2N5 influenza virus isolates from terns in Australia: genetic reassortants between those of the Eurasian and American lineages. Virus Genes 37, 16-21 (2008)

26. K. Sharshov, N. Silko, I. Sousloparov, A. Zaykovskaya, A. Shestopalov, I. Drozdov, Avian influenza (H5N1) Outbreak among Wild Birds, Russia, 2009. Emerg. Infect. Dis. 16, 349-351 (2010) 